
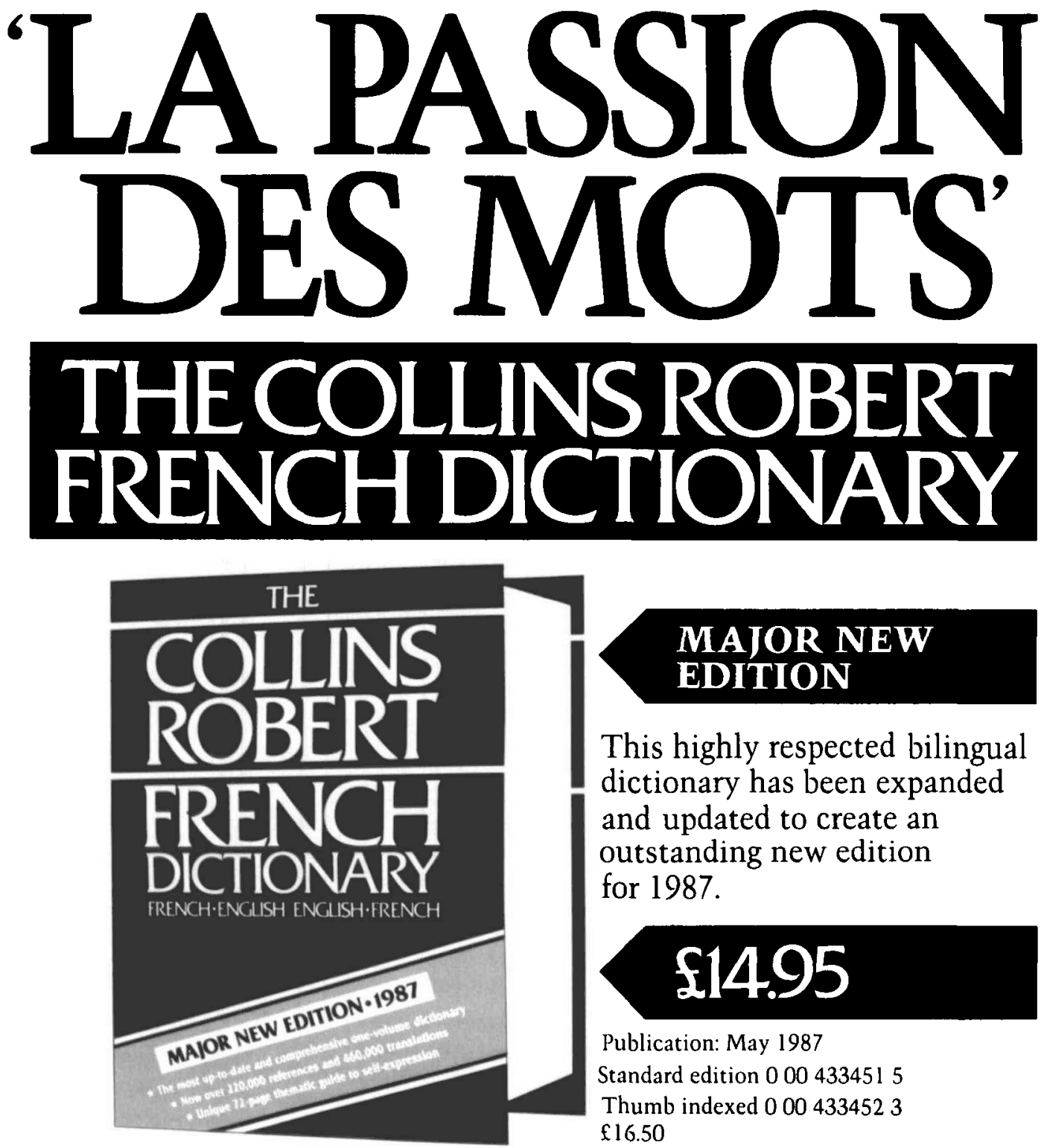

This highly respected bilingual dictionary has been expanded and updated to create an outstanding new edition for 1987.

\title{
$£ 14.95$
}

Publication: May 1987

Standard edition 0004334515

Thumb indexed 0004334523

$£ 16.50$

* Now with over 460,000 translations

* Contains a unique 72 page 'Language in Use' section to help the non-native speaker achieve natural self-expression

* Meaning and usage clearly signposted so the reader can quickly and easily find the translation needed

* Exceptionally clear layout

THE MOST UP-TO-DATE AND

COMPREHENSIVE ONE VOLUME

DICTIONARY FOR FRENCH STUDIES AND

TRANSLATION NEEDS. 
The international abstracting journal

for language teachers and applied linguists

April 1987 Volume 20 no 2

\section{Contents}

State of the art

Michael P. Breen on contemporary paradigms in syllabus design

Abstracts

Language learning and teaching -

136-191 theory and practice

$192-216$

Teaching particular languages

$217-271$

Research in the supporting sciences

$272-286$

Language description and use

New books

Bibliographies

List of abstractors

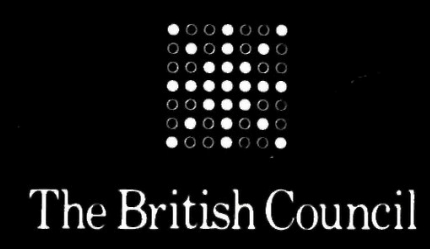

\section{CIIT}

\section{Cambridge University Press}

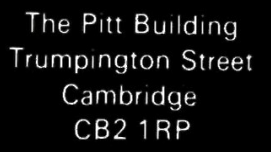
32 East 57 th Street New York NY10022 USA

